Lisbon - Malacca Port Cities Twin Conferences 2019 / 2020

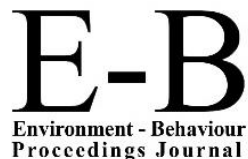

\title{
The Development and Validation of Pre-Driving Assessment: Attitude towards safe driving scale
}

\author{
Mohamad Ghazali Masuri1, Akehsan Dahlan1, Khairil Anuar Md Isa2, Rugayah Hashim3 \\ 1 Occupational Therapy Department, \\ 2 Basic Sciences Department, \\ Faculty of Health Sciences \\ ${ }^{3}$ Research \& Innovation Division, \\ Universiti Teknologi MARA
}

zalie222@gmail.com akehsan.dahlan@yahoo.com khairil_hpm@hotmail.com guy73106@yahoo.com

Tel: 0196259314

\begin{abstract}
An occupational therapist who involved with driving rehabilitation should use a proper evaluation in identifying safe driving behaviour during the predriving assessment. Many reports have stated that human factors contributed up to $97 \%$ of collision. This study aims to develop a psychological evaluation that measures human factors in traffic safety during the pre-driving assessment. This study was involved sequential mix methodology approach. The factor analysis was carried out to determine the validity and reliability of the evaluation (Cronbach alpha .887). This assessment found to be adequate in providing the standard means of risky driving attitude based on the cut off value established.
\end{abstract}

Keywords: Occupational science; Pre-driving assessment; Functional activities; Driving rehabilitation

eISSN: 2398-4287 @ 2020. The Authors. Published for AMER ABRA cE-Bs by e-International Publishing House, Ltd., UK. This is an open access article under the CC BYNC-ND license (http://creativecommons.org/licenses/by-nc-nd/4.0/). Peer-review under responsibility of AMER (Association of Malaysian Environment-Behaviour Researchers), ABRA (Association of Behavioural Researchers on Asians) and cE-Bs (Centre for Environment-Behaviour Studies), Faculty of Architecture, Planning \& Surveying, Universiti Teknologi MARA, Malaysia.

DOI: https://doi.org/10.21834/e-bpj.v5i13.2060

\subsection{Introduction}

Road safety and road traffic accident (RTA) is a complex phenomenon involving multiple components, namely human, machine and environment. As stated by Masuri, Dahlan, Danis and Isa (2014a, 2014b), driving is one of the prominent examples of complex daily activities which comprise the coordination of active eye, hand, and foot. RTA is one of the leading cause of premature death (Adria Spoerri, 2011), and it is crucial to scrutinize the solution to reduce its mortality rate. RTA has become a major concern and health-related problem in worldwide. Rehabilitation professionals such as occupational therapist commonly encounter patient/client with multiple difficulties in their daily life, including driving performance prior to the injury. The roles of the occupational therapist in work, including driving rehabilitation, have long-established and recognized by Malaysian authorities such as the Road Transport Department. It is clearly stipulated under few documents for example; Medical examination standards for disabled driver's licensing year 2011 and the Road Transport Act 1987 (Act 333) explain under few sections such as; 5(1), 30(1) (2a, b) (3) (4), 46 and 56(4ai, ii, b) (International Law Book Services. 2015). This complexity deserves extra attention from an occupational therapist to further understand and investigate the physical and psychological components of the drivers using theoretical knowledge of occupational science.

eISSN: 2398-4287 @ 2020. The Authors. Published for AMER ABRA cE-Bs by e-International Publishing House, Ltd., UK. This is an open access article under the CC BYNC-ND license (http://creativecommons.org/licenses/by-nc-nd/4.0/). Peer-review under responsibility of AMER (Association of Malaysian Environment-Behaviour Researchers), ABRA (Association of Behavioural Researchers on Asians) and cE-Bs (Centre for Environment-Behaviour Studies), Faculty of Architecture, Planning \& Surveying, Universiti Teknologi MARA, Malaysia.

DOI: https://doi.org/10.21834/e-bpj.v5i13.2060 
According to a textbook of driving psychology (Fuller, 2011), the driver's performance might be perceived based on two essential elements; driving skills or driving style. In general, driving skills can be defined as the driver's ability and capability to control their vehicle. Driving style, on the other hand, refers to individual preference or practice in driving. Noticeably, these two elements require human cognition in processing and decision making while driving. Skills in driving could be learned either by formal education or by practical training and could be improved by time as a proper practice is one of the crucial factors to enhance skills.

In contrast, the styles of driving were greatly influenced by the environment and surroundings, as stated by Abang Mustaffa, Masuri, Dahlan, and Md. Isa (2015), which discovered that the influence of intimates or person is accompanying the drivers impose dissimilarity in compliance with traffic rules and regulations. This ambiguous disparity offers a fascinating opportunity to investigate the psychological element of Malaysian drivers further. However, there was limited evidence available to unravel this perplexing relationship among local drivers. The current study believes that it is important to develop an understanding of psychological components among competent drivers, which later may be used as a reference standard for driving rehabilitation programme.

Driving plays an essential role in human life as it enables people to travel from one place to another. This activity may involve several modes of transportation such as personal or public transportation (Masuri, Dahlan, Danis \& Md Isa, 2016), and it is categorized as one of the occupational performance areas. Notably, using personal transportation is preponderance in Malaysia instead of public transport. In general, driving is a daily multiplex activity and involving multidimensional concept. This study believes that there is a necessity to improve the tools or outcome measures and frameworks utilized for various intervention targets, especially among the vulnerable groups of the population to achieve the optimum outcome. Therefore, measuring the road user's attitude and safety scale at national, regional, and community levels is pivotal to develop the appropriate policy and programme options.

The questionnaire is one of the most common outcome measures which have been adopted in occupational therapy practice (Kielhofner, 1995). A well-designed questionnaire is imperative as it serves two important purposes; to be used as exploratory information or to test the specific hypothesis. Conventionally, the data collected in the exploratory questionnaire would not be statistically evaluated as it might be in the form of interview and exploration of an issue. However, it should be attentively executed where a formal questionnaire may restrict the area of discussion and prevent from a complete exploration of an issue. Standardized assessment, on the other hand, could provide the numerical or specific quantity following statistical evaluation. Accordingly, the hypothesis testing will be utilized to validate the values of current data in comparison with previous findings or references. For example, with regards to the driver's attitude, the researcher might be interested in studying the difference between demographic data such as gender, marital status and et cetera.

Pertaining to the complexity, multidimensional nature and strong subjective element of the human attitude, it is intricate to identify a single standard against which the attitude scale can be validated. Therefore, attitude measurement tools or outcome measures need to be assessed through a diversified perspective. As suggested by Crawford (1990), three important resources should be referred in the process of questionnaire development; exploratory interviews with experts, searching for secondary data, and review from individual whom experienced the phenomena. In addition, the entire information should be careful 'blend' and analyzed. Once the rough questions have formed, it shall undergo another intricate mathematical analysis, namely validation study.

As far as this study is a concern, it is critical for researchers, policymakers, governmental and non-governmental agencies, and all interested sectors to invest their time and resources in the process of developing such tools that provide valid and reliable measures of driver's attitude in Malaysia. Finally, according to Kraus, (1995), the standardized assessment provides the essential information that will support several circumstances of the profession such as to measure, evaluate and demonstrate the effectiveness of interventions with service users and caregivers. Besides, the standardized assessment also plays an important role as indicators of professional status (Managh \& Cook, 1993). As a summary, a well-designed questionnaire is essential to develop an effective and successful survey. Additionally, a simple and meaningful question will lead to accurate data and information, which finally helps this study to achieve the objective.

The aim of this study is to explore the psychometric properties of driver's attitude towards safe driving practice. Finally, this study established an appropriate attitude components of safe driver's. This paper also intended to validate the Bahasa Malaysia version of ASDS according to first schedule (section 2) of Act 333 Road Transport Act 1987. This evaluation could be used in screening and reevaluation process of licensing in Malaysia. The newly developed evaluations were tested for its psychometric properties, and it is subject to cognitive testing. The validity and reliability of the new questionnaire were tested, while the relationship between drivers demographic and safety characteristics was explored in details.

\subsection{Method}

This study was involved sequential mix methodology approach. A one-to-one semi-structured interview was conducted, involved three experts, two accident witness/victim and six victims. The verbatim transcripts were analyzed by using six steps Interpretative Phenomenological Analysis. Six super-ordinate themes emerged that describes the expert views, victim and witnesses experiences towards RTA. Themes and sub-themes that emerged from the interview later translated into 46 attitudes based questionnaire, namely; Attitude towards Safe Driving Scale (ASDS). The stem of the 46 questions was based on the themes and sub-theme.

\subsection{Result}

A total of 694 students aged 19 to 32 years participated in this study. A majority of the respondents were females (78.8\%), followed by males (21.2\%). Majority of the respondents came from rural area 366 (52.7). In addition, the majority of respondents possess a valid 
driving licence and have driving experience of more than 12 months (75.4\%). Table 1 shows the demographic characteristics of all respondent for this study.

Table 1. Demographic characteristics of study population.

\begin{tabular}{llll}
\hline & & $\mathbf{n}$ & $\%$ \\
\hline Gender & Male & 147 & 21.2 \\
Age & Female & 547 & 78.8 \\
& $17-19$ & 38 & 5.5 \\
& $20-22$ & 428 & 61.7 \\
& $23-25$ & 199 & 28.7 \\
Place of origin & 26 and above & 29 & 4.2 \\
& urban & 303 & 43.7 \\
Income (RM) & rural & 366 & 52.7 \\
& not sure & 25 & 3.6 \\
& $0-500$ & 316 & 45.5 \\
Distance travel in 12 months (KM) & $501-1000$ & 149 & 21.5 \\
& $1001-1500$ & 26 & 3.7 \\
& $1501-2000$ & 24 & 3.5 \\
& Above 2000 & 94 & 13.5 \\
& $0-500$ & 413 & 59.5 \\
Victim & $501-1000$ & 103 & 14.8 \\
Driving experience & $1001-1500$ & 11 & 1.6 \\
& $1501-2000$ & 16 & 2.3 \\
Licence duration & $2000-5000$ & 38 & 5.5 \\
& Above 5001 & 107 & 15.4 \\
& Yes & 226 & 32.6 \\
& No & 468 & 67.4 \\
& Yes & 132 & 19.0 \\
& No & 562 & 81.0 \\
& Less than 12 months & 171 & 24.6 \\
& More than 12 months & 523 & 75.4 \\
& Less than 12 months & 171 & 24.6 \\
& More than 12 months & 523 & 75.4 \\
\hline
\end{tabular}

Table 2 shows the distribution of offences among respondent towards ten common road traffic offences. Driving exceeding the speed limit is listed at number one followed by overtaking at the double line, not giving a signal, not using a safety belt, do not comply with a traffic sign, driving in the emergency lane, cause of accident, queue-jumping, and not respecting others. However, many respondents also declared that they have difficulty to remember either they had to commit an offence for the last 12 months.

Table 2. Traffic Offences among Study Population.

\begin{tabular}{llll}
\hline Offences & Yes $(\mathbf{n})$ & No $(\mathbf{n})$ & Not sure (n) \\
\hline (i) Driving above the speed limit & 299 & 338 & 57 \\
(ii) Failure to comply with traffic sign & 206 & 488 & - \\
(iii) Overtaking at double lines & 287 & 344 & 63 \\
(iv) Driving in emergency lanes & 116 & 471 & 107 \\
(v) Queue-jumping & 78 & 506 & 110 \\
(vi) Using mobile phones while driving & 42 & 535 & 117 \\
(vii) safety belt & 232 & 397 & 65 \\
(iix) signaling & 248 & 374 & 72 \\
(ix) cause of accident & 85 & 495 & 114 \\
(x) respect to others & 28 & 542 & 124 \\
\hline
\end{tabular}

The identification name of domains is believed to be necessary where it will be used as a future referral. During this process, all panel of experts (R7, R8 and R11) were invited for discussion. At the end of the session, the domain name was given. Table 3 shows the process of naming the domain. The creation of each name of the domain was based on the top three items that received the highest alpha value.

Table 3. Domains name

\begin{tabular}{lll}
\hline Domain & \multicolumn{1}{c}{ Top three questions } & \multicolumn{1}{c}{ Domain's new name } \\
\hline D1 & Q26, Q28 and Q30 & Self-complaint \\
D2 & Q2, Q3 and Q12 & Self-confidence \\
D3 & Q1, Q10 and Q11 & Self-benefit \\
D4 & Q31, Q33 and Q35 & Self-concern \\
D5 & Q7, Q8 and Q9 & Self-style \\
\hline
\end{tabular}




D6 Q4, Q5 and Q6 Self-preparedness

Table 4 shows the mean value of scores from each domain, including the total count of ASDS. The mean value from this score was used as a cut-off value to determine high and low-risk drivers. The general rule of an increasing number of score to represents a better and more positive result was applied. Meaning that any scoreless then the mean depicts that the respondent is categorized as high-risk drivers.

Table 4. Mean cut-off of high and low risk drivers for each domains.

\begin{tabular}{|c|c|c|c|c|c|c|c|}
\hline \multicolumn{8}{|c|}{ Statistics } \\
\hline & D1 & D2 & D3 & D4 & D5 & D6 & TOTAL RISK \\
\hline Mean & 45 & 36 & 32 & 20 & 12 & 9 & 157 \\
\hline Mode & 39.00 & 37.00 & 32.00 & 18.00 & 12.00 & 9.00 & $155.00^{a}$ \\
\hline Std. Deviation & 9.757 & 5.231 & 4.267 & 3.843 & 2.699 & 2.209 & 16.503 \\
\hline Minimum & 13.00 & 15.00 & 16.00 & 6.00 & 4.00 & 3.00 & 94.00 \\
\hline Maximum & 65.00 & 50.00 & 40.00 & 30.00 & 20.00 & 15.00 & 220.00 \\
\hline Sum & 31351 & 25515 & 22878 & 14489 & 8494 & 6734 & 109461 \\
\hline Definition & $H<45>L$ & $H<36>L$ & $H<32>L$ & $H<20>L$ & $H<12>L$ & $H<9>L$ & $H<157>L$ \\
\hline $\begin{array}{l}\text { Multiple } \\
\mathrm{H}=\mathrm{High}\end{array}$ & xist. The sr & value is $p$ & nted & & & & \\
\hline
\end{tabular}

\subsection{Discussion}

Content validity - Expert Analysis.

From this study, the ASDS shown to be adequate in term of validity and is a reliable measurement to be used to assess drivers' attitude. However, caution should be made that ASDS had never been translated into other language or being tested. The reviewer comments were explicitly in respond towards how the study population understand and respond towards the assessment and language used maintaining the social and cultural of the respondent. This study also provides an evident that ASDS meets the acceptable level of content validity, face validity, internal consistency, and criterion validity.

\section{Pretesting - Face Validity.}

With regards to face validity, most respondents were able to understand and comprehend wits ASDS items. Since the review of the literature did not reveal any comparable local study, therefore no comparison was made during the discussion of this issue. This discussion shall be used as a critical direction for the assessment of face validity in forthcoming studies. In general, when asked "what did you understand from that question?" for each item, most respondents were able to express the exact meaning according to the question stem. All of the respondents were also able to read and comprehend the meaning of those items. No further issues were observed in this study stage.

\section{Construct Validity.}

In the present study, six main factors emerged from the rotated principal factor analysis: D1 - D6. It was also observed that those factors explained $65 \%$ of the variance in respond, where an Eigenvalue $>1.3$ was considered as significant. The Cronbach's a was estimated at 0.855 , which indicates satisfactory internal consistency. Question 1 (Q1, Alpha value at 0.854 ), which in domain 1 falls under the category of 'observable question' or opening question. This opening question usually refers to an introduction to the topic. The stem of Q1 was looking at the degree of the respondent's agreement regarding attitude as the cause of RTA. Majority of the respondents strongly agreed that driver's attitude is the main cause or RTA, and this was similar with reports from a few works of literature such as the PDRM and driving alert Magazine. On the final version, Q27 and Q29 were removed since its factor loading were less than 0.4 .

\section{Reliability.}

The internal consistency of ASDS in phase 2 of the current study is comparable with stage 1, wherein this phase, the Cronbach's Alpha was observed to be at 0.6 to 0.9 . In the present study, the Cronbach's alpha was found to be within $0.83-0.85$. Accordingly, phase 2 analysis shows no significant difference compared with the result from the previous phase. The latest study on ASDS had shown a fascinating negative correlation between ASDS and internet addiction test (IAT). The association for six domains of the ASDS and IAT level has been conducted using the Pearson Correlation Coefficient ( $r$ ). The evaluation showed that the correlation ranges from -0.095 to -0.225 , which indicates that there was a negative correlation between these two variables. Therefore, the result suggests that if one variable increase or having a high score, the other variable will decrease or showing the low score. In particular, the degree of relationship can be identified by using Sig or probability $(p)$ value of .05 or less, and the Ho are failed to reject because there is a statistically significant relationship between these pairs of domains of ASDS and IAT level. Three domains significantly correlated with each other. The correlations occurred at D1 (self-compliant), D2 (self-confidence), and D4 (self-concern).

D1; it proves that the respondents who are addicted to the internet will use possible opportunity and space to violate road rules and safety. It is due to the personality of type A as Nabi (2005) found that this type of person has been suspected to be associated with risky driving behaviour and lead to RTA. D2; it marks that the respondents who have high internet addiction level, also have a high level of self-confidence to execute RTA offences. According to Scott-Parker, Watson, King, and Hyde (2011), the drivers who had their cars 
have higher mileage and riskier driving because they are extraordinarily confident and comfortable with unsafe driving. D4; the respondent who has internet addiction has a high hope and self-centred or morbid concern for oneself to ignore the road traffic legislation. Possibly, the driving experience could be a predictor for driving safety as they have skills-oriented driving and high ability to manoeuvre the car, even though they have high exposure toward road violation. Life experiences among young adults will compromise many challenges, such as new driving experience, cognitive, and psychosocial maturity. The trials will offer opportunity and threat towards their future life. As a young adult, they are usually having difficulty to choose and make a wise decision about their action. This immaturity, especially in driving, behaviour leads to high-risk behaviour. However, little information about this issue is available, especially among Malaysia.

\subsection{Conclusion}

The use of valid and reliable assessment tool is vital for all of us, including health professionals such as occupational therapy. A valid and reliable tool that can be easily used at the field level has long been necessitated in this country. Malaysian occupational therapist having a great challenge in making a decision on appropriate measurement tools due to availability and administrative issue. For example, the therapist will usually refer to the only guideline published by the Occupational Health Unit, Disease Control Division, Ministry of Health, Malaysia. That document entitles medical examination standards for disabled driver's licensing only highlight the 2.5 , 2.8 and 3.1, which no evidence of attitude elements. The therapist who involved in driving rehabilitation fully agreed that the psychological readiness of disabled drivers also needs to be assessed prior to their injury or disease. This created a huge demand and debate among therapist regarding which elements need to be assessed in driving rehabilitation programme. Each therapist will use their initiatives to search and start to develop their own 'protocol', and this scenario offers for non-standardized protocol and the result may be challenged in the future. In fact, this study and the process of questionnaire development has generated considerable interest from a local therapist. The complexity and multidimensional nature of the driver's attitude issue have led to difficulty in identifying the gold standard for validation purposes. However, this study has undergone a lengthy process of development of its own 'gold standard' during the pilot study. The published result then referred for the other analysis in this study. The present study is among the first to develop and examine the content validity of drivers attitude in Malaysia context. As mentioned earlier, the unavailability of local information and limited work on questionnaire development become the biggest challenge in the statistical process, including validation and hypothesis testing. Hopefully, the previously published research may assist the rest of this discussion process. The findings of this present study make significant contributions to the existing literature, especially in the Malaysia perspective by highlighting the cross-cultural differences and similarities since the majority of the current research were conducted outside Malaysia. This study enabled us to clarify the measurement, and the high score in IRA shows that the majority of experts agreed with each other.

This shows that the ASDS measure has gained adequate agreement and suitability for measuring risky attitude among young Malay drivers. In this study, all experts were simultaneously analyzed together, and there were no differences between the lay and professional experts, which results in strong CVI. All experts agreed with the contents of the ASDS, and therefore, there is no revision needed to improve the measure. Findings also indicated that the wording in the items was representative and clear. Thus, the text of ASDS items is not required to be revised.

Caution only needs to be taken while applying the cut-off levels using the validation of a specific item to indicate the transition across a threshold from low and high-risk attitude. This cut-off could be tolerated since this present study only focuses on Malay drivers.

Intense testing of ASDS has confirmed the ability to measure risky attitude and its conceptual framework. This study disclosed a right internal scale construct validity and person respond validity. The result also depicted strong validity between all six domains. Hence, ASDS could be used for further exploration of the driver's attitude in identifying the specific domain-based problem.

\section{Acknowledgements}

The highest appreciation goes to the Ministry of Higher Education Malaysia (MoHE), Royal Malaysia Police, Research Management Centre (RMC) Universiti Teknologi MARA (UiTM), CoRe Management Science, OPERA RIG, and all staff of the Faculty of Health Sciences UiTM Puncak Alam for continuous support in staff research and development. Thank you to our strategic partner, Ministry of Health, NIOSH Malaysia, DOSH and our future international collaborators: Tokyo University of Technology, Japan, Honam University, South Korea and Universiti Indonesia, Indonesia. Lastly, specially mentioned to our beloved friend and research team; Allahyarham Anniz Fazli Ibrahim Bajunid. This study was funded under the Fundamental Research Grant Scheme (FRGS) by MoHE - (600IRMI/FRGS 5/3 (126/2019).

\section{References}

Abang Mustaffa, D. N., Masuri, M. G., Dahlan, A., \& Md. Isa, K. A. (2015). The Intention In Speeding Behavior Between Low And High Intended Young Driver's In Urban University. Paper presented at the Asia Pacific International Conference on Environment-Behaviour Studies, Barcelona School of Architecture (ETSAB), Universitat Politechnica De Catalunya (UPC), Barcelona, Spain.

Adria Spoerri, M. E. E. v. E. (2011). Mortality from road traffic accident in Switzerland : Longitudinal and spatial analyses. Accident Anaysis \& Prevention, 43(1), 40-48. 
Alert Driving Megazine, (2011). Human error accounts for $90 \%$ of road accidents. International News. Retrieved from http://www.alertdriving.com/home/fleet-alertmagazine/international/human-error-accounts-90-road-accidents

Crawford, I. (1990). Marketing Research Centre for Agricultural Marketing Training in Eastern and Southern Africa.

Fuller, R. (2011). Chapter 2 - Driver Control Theory: From Task Difficulty Homeostasis to Risk Allostasis. In B. E. Porter (Ed.), Handbook of Traffic Psychology (pp. 1326). San Diego: Academic Press

International Law Book Services. (2015). Road Transport Act 1987. Petaling Jaya: International Law Book Services.

Kielhofner, G. (1995). A Model of Human Occupation: theory and application (2nd ed.). Maryland: Williams \& Wilkins.

Kraus, S. (1995). Attitudes and the prediction of behavior. A Meta Analysis of the Empirical Literature. . Personality and Social Psychology Bulletin, $21,58-75$.

Managh, M. F., \& Cook, J. V. (1993). The Use of Standardized Assessment in Occupational Therapy: The BaFPE-R as an Example. American Journal of Occupational Therapy, 47(10), 877-884. doi:10.5014/ajot.47.10.877

Masuri, M. G., Dahlan, A., Danis, A., \& Isa, K. A. M. (2014a, 24-26 February 2014). Public participation in shaping better Malaysian's road society in the future. Paper presented at the AicE-Bs2014Berlin Berlin, Germany.

Masuri, M. G., Dahlan, A., Danis, A., \& Isa, K. A. M. (2014b, 25-27 August 2014). Regeneration of Road System in the Urban Environment: Will Rehabilitation Components Orientate Road Users? Paper presented at the AcE-Bs2014Seoul, Chung-Ang University, Seoul, S. Korea.

Masuri, M. G., Dahlan, A., Danis, A., \& Md Isa, K. A. (2016). Attitude towards Safe Driving Scale (ASDS) As a Future Predictor in Determining a Young Adult Quality Of Life: Part I. Procedia - Social and Behavioral Sciences, 234, 390-397. doi:https://doi.org/10.1016/j.sbspro.2016.10.256

Masuri, M. G., Dahlan, A., Md Isa, K. A., Danis, A., Natar, A. K. M., Thanapalan, C. K. K., .. Yusoff, M. N. M. (2014). The Use of Protection Motivation Theory (PMT) in developing Malaysian Driver's Attitude Evaluation. Paper presented at the CHUSER2014, Penang Malaysia in press.

Masuri, M. G., Md Isa, K. A., \& Mohd Tahir, M. P. (2012). Children, Youth and Road Environment: Road Traffic Accident. Procedia - Social and Behavioral Sciences, 38(0), 213-218.

Masuri, M. G., Md Isa, K. A., Mohd Tahir, M. P., Hassan, H. F., Hassan, Z., Jamhuri, F. Z., . . Noor, S. H. (2012). Behaviour Response among Health Sciences Students towards H1N1 Pandemic. Procedia - Social and Behavioral Sciences, 36(0), 77-86. doi:10.1016/j.sbspro.2012.03.009

Md Isa, K. A., Masuri, M. G., Abd Aziz, N. A., Md Isa, N. N., Hazali, N., Mohd Tahir, M. P., ... Hassan, H. F. (2012). Mobile Phone Usage Behaviour while Driving among Educated Young Adults in the Urban University. Procedia - Social and Behavioral Sciences, 36(0), 414-420.

Scott-Parker, B., Watson, B., King, M. J., \& Hyde, M. K. (2012). Confirmatory factor analysis of the Behaviour of Young Novice Drivers Scale (BYNDS). Accident Analysis \& Prevention, 49(0), 385-391.

Wan Ahmad Kamal, W. N. H., Masuri, M. G., Dahlan, A., \& Md Isa, K. A. (2015). Seat Belt Compliance and Quality of Life among Educated Young Adults in an Urban University. Procedia - Social and Behavioral Sciences, 202, 442-447. doi:http://dx.doi.org/10.1016/j.sbspro.2015.08.249 